\title{
Strain Measurement Using Embedded Fiber Bragg Grating Sensors Inside an Anchored Carbon Fiber Polymer Reinforcement Prestressing Rod for Structural Monitoring
}

Kerrouche, Abdelfateh; Boyle, William J.O.; Sun, Tong; Grattan, Kenneth T. V.; Schmidt, Jacob Wittrup; Täljsten, Björn

Published in:

I E E E Sensors Journal

Link to article, DOI:

10.1109/JSEN.2009.2018355

Publication date:

2009

Document Version

Publisher's PDF, also known as Version of record

Link back to DTU Orbit

Citation $(A P A)$ :

Kerrouche, A., Boyle, W. J. O., Sun, T., Grattan, K. T. V., Schmidt, J. W., \& Täljsten, B. (2009). Strain Measurement Using Embedded Fiber Bragg Grating Sensors Inside an Anchored Carbon Fiber Polymer Reinforcement Prestressing Rod for Structural Monitoring. I E E E Sensors Journal, 9(11), 1456-1461. https://doi.org/10.1109/JSEN.2009.2018355

\section{General rights}

Copyright and moral rights for the publications made accessible in the public portal are retained by the authors and/or other copyright owners and it is a condition of accessing publications that users recognise and abide by the legal requirements associated with these rights.

- Users may download and print one copy of any publication from the public portal for the purpose of private study or research.

- You may not further distribute the material or use it for any profit-making activity or commercial gain

- You may freely distribute the URL identifying the publication in the public portal 


\title{
Strain Measurement Using Embedded Fiber Bragg Grating Sensors Inside an Anchored Carbon Fiber Polymer Reinforcement Prestressing Rod for Structural Monitoring
}

\author{
Abdelfateh Kerrouche, William J. O. Boyle, Tong Sun, Kenneth T. V. Grattan, Jacob W. Schmidt, and \\ Björn Täljsten
}

\begin{abstract}
Results are reported from a study carried out using a series of Bragg grating-based optical fiber sensors written into a very short length $(60 \mathrm{~mm})$ optical fiber network and integrated into carbon fiber polymer reinforcement (CFPR) rod. Such rods are used as reinforcements in concrete structures and in tests were subjected to strain through a series of cycles of pulling tests, with applied forces of up to $30 \mathrm{kN}$. The results show that effective strain measurements can be obtained from the different sensors mounted along the rod. Additionally, the tests show that close agreement with the results obtained from the calibrated force applied by the pulling machine and from a conventional resistive strain gauge mounted on the rod itself is obtained. Calculations from strain to shear stress show a relatively uniform stress distribution along the bar anchor used. The results give confidence to results from various methods of in situ monitoring of strains on such CFRP rods when used in different engineering structures.
\end{abstract}

Index Terms-Anchor system, carbon fiber polymer reinforcement (CFPR), fiber Bragg grating (FBG), prestressing rod.

\section{INTRODUCTION}

$\mathbf{O}$ VER the past few years, carbon fiber reinforced polymer (CFRP) composites have become increasingly accepted materials for external strengthening, in particular, as sheets and plates but also as rods, (usually as internal reinforcement in the form of rods) in concrete structures. Their uses arises from their high corrosion resistance and high strength-to-weight and stiffness-to-weight ratios which make CFRP composites very well suited to these applications, when compared, for example, to steel reinforcement rods. Systems have also been developed for prestressing, [1]. It should be noted that however, field applications for prestressing are relatively uncommon. One reason for this is the lack of cost-effective anchor systems. To anchor a CFRP tendon is more complicated than for a similar steel

Manuscript received October 16, 2008; accepted December 16, 2008. Current version published September 23, 2009. This work was supported in part by the EU FP6 Integrated Project: Sustainable Bridges Project and in part by EPSRC. The associate editor coordinating the review of this paper and approving it for publication was Dr. Subhas Mukhopadhyay.

A. Kerrouche, W. J. O. Boyle, T. Sun, and K. T. V. Grattan are with the School of Engineering and Mathematical Sciences, City University, London EC1V 0HB, U.K. (e-mail: Abdel.kerrouche.1@ @ity.ac.uk; W.J.O.Boyle@city.ac.uk; T.Sun@city.ac.uk; K.T.V.Grattan@city.ac.uk).

J. W. Schmidt and B. Täljsten are with the Technical University of Denmark, 2800 Kgs. Lyngby, Denmark (e-mail: bt@byg.dtu.dk).

Color versions of one or more of the figures in this paper are available online at http://ieeexplore.ieee.org.

Digital Object Identifier 10.1109/JSEN.2009.2018355 system. The main reason for this is the weak material properties of the CFRP in the radial direction; the tendon is sensitive to high concentrated forces. To overcome this, it is necessary to create anchor systems that distribute the shear stresses and minimizes the peak stresses of the anchor. Research is ongoing on a new type of wedge anchor, but not presented in detail in this paper as it is the subject of an ongoing patent application [2], [3]. To investigate the shear stresses at the surface between the CFRP tendon and the wedges, fiber-optic techniques have been proposed and investigated, with the results presented in this paper.

In the development of the anchor for the CFRP rods, the aim of the work carried out within a limited timescale has been to obtain failure outside the anchor, in the tendon itself. Thus, in light of the increasing use and potential of such anchor systems for a variety of civil engineering applications, a series of novel strain measurements from CFRP rods inside an anchor system have been taken. These have been designed to allow the investigation of the strain distribution along the rod and thus (in subsequent work) coupling the results to those from a finite-element model study. The work builds upon the expertise of the investigators in the use of fiber Bragg grating sensors (FBGs) to make strain measurements along conventional reinforcement bars [4]. In this application to our knowledge, for the first time FBGs have been used for monitoring the stains in the anchor. To do so a series of FBG sensors is fabricated along a very short length of fiber to allow measurements to be taken over a minimal length of CFRP bar. FBGs are now an increasingly accepted technology offering a number of advantages for many engineering applications such as structural health monitoring, damage assessment and in monitoring engineering materials [5], [6]. Such sensors have been successfully used in several engineering fields to measure strain, temperature, pressure and monitoring applications for industrial and civil structures [7]-[10].

In this application, arising from the difficulty of measuring strain inside the anchor system, the approach of using several FBG sensors over a short length of fiber was the only possibility to enable successful measurements. The advantages here of using the FBG sensors arise from their relatively small physical size ( $<$ a few $\mathrm{mm}$ in length) compared to conventional strain gauges, thus making them much more suitable for embedding in structures in general or in CFRP composites in this case. In addition, the use of these sensors does not cause any significant changes to the mechanical properties of the host material. The 


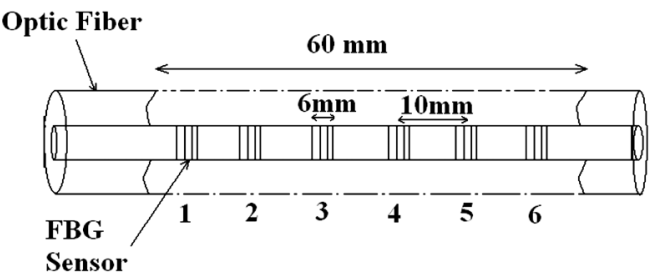

Fig. 1. Schematic of the placement of the six different FBG sensors written along the $60 \mathrm{~mm}$ length of the optical fiber.

details described subsequently will show that in this application, the single FBG network created shows advantages over the use of conventional strain gauges for strain measurement.

\section{THE EXPERIMENTAL ARRANGEMENT USED}

\section{A. FBG Sensor Writing and Sensor Arrangement}

For this application, six FBG sensors were fabricated, in-house, on a very short length $(60 \mathrm{~mm})$ of stripped optical fiber to enable strain measurements to be made over that same short length of CFRP rod to which the fiber would be attached. It was, therefore, a key (and difficult) challenge to overcome to create the right fiber network of this type of relatively short length. To do so, the following procedure was employed.

Initially, the required length of fiber into which the different FBG sensors were to be written was stripped and, using phase mask technique [5], all the sensors were written manually by shifting the fiber by $10 \mathrm{~mm}$ on each occasion, while at the same time changing the corresponding phase mask to allow a series of different sensors at wavelengths separated by $\sim 5 \mathrm{~nm}$ to be written. Fig. 1 shows this schematically. In practice, the stripped fiber is very fragile and considerable care has to be taken to allow the short network to be created. This also makes it very difficult to install the network onto the CFRP rod and for this reason, the packaging and installing of sensors onto such a rod requires particular care to avoid damage to the fiber and thus the sensors.

\section{B. Sensor Attachment to the CFRP-Anchor System}

A CFRP rod of nominal diameter of $8 \mathrm{~mm}$ was employed using the newly developed wedge anchor system with a copper sleeve to prevent crushing of the fibers due to direct contact between the wedges and CFRP rod. The optical fiber, with the six FBG sensors written into it, was glued (using a cyanoacrylic adhesive) inside a groove of $2 \mathrm{~mm}$ wide and $1 \mathrm{~mm}$ deep which was cut along $50 \mathrm{~cm}$ rod to hold and protect the optical fiber. The optical fiber was placed in such a way that the five FBG sensors are located inside and one FBG sensor outside the anchor system.

For comparison, a single electrical resistance strain gauge was fixed onto the CFRP near the wedge end of the anchor and several such gauges were also placed outside on the steel casing of the anchor system to provide some comparative measurements. Given its size, the only realistic option available to take measurement inside the anchor was via optical fiber. Schematic diagrams of the arrangements used are shown in Fig. 2(a)-(c).

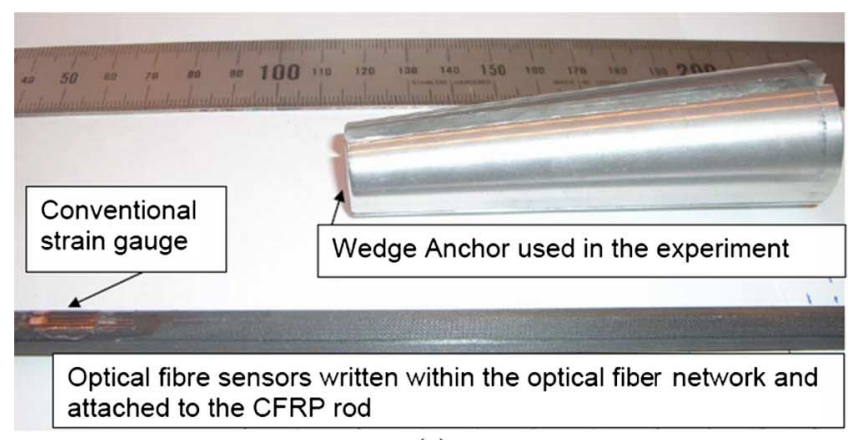

(a)

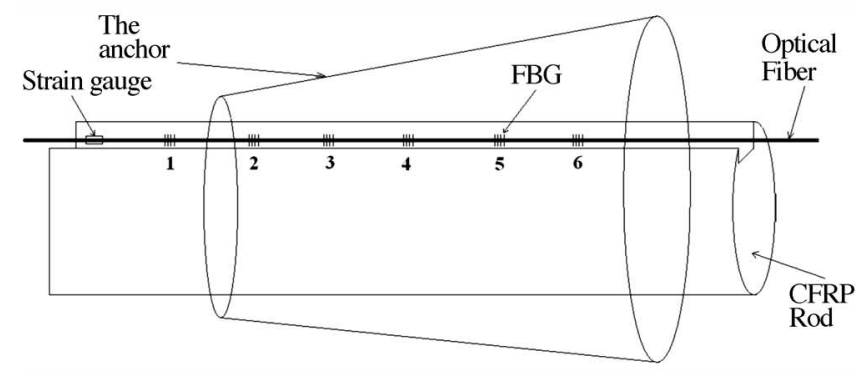

(b)

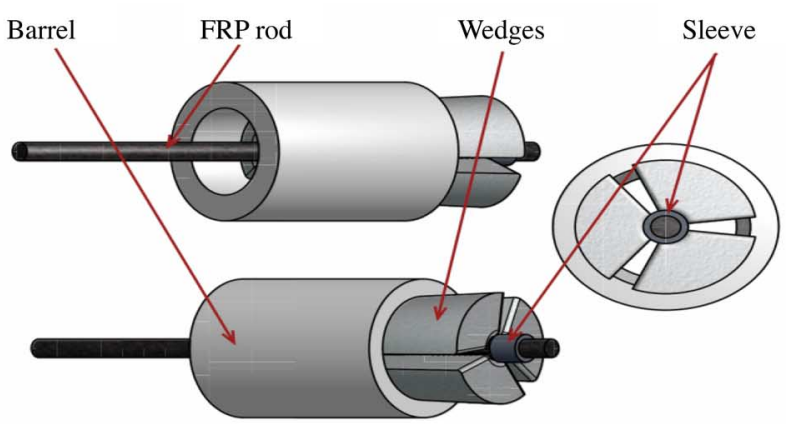

(c)

Fig. 2. (a) Photograph showing the wedge anchor, the optical fiber sensor network and the conventional strain gauge. (b) Schematic of the CFRP-anchor showing its position relative to the optical fiber sensors used and FBG2-6 within the anchor with FBG1 outside. (c) View of the wedge anchor showing barrel, wedges, and sleeve.

\section{The Sensor Interrogation System Used}

The FBG network in this application was interrogated by using the well known wavelength division multiplexing (WDM) approach, which uses the different characteristic sensor wavelengths to identify one sensor from another along the network. This was similar to that used by the authors previously [11], [12], where the array of sensors was illuminated by light from a broadband source and detected using an optical spectrometer containing a Fabry-Perot tuneable filter that scans the narrow band light from the source and sweeps over wavelength of the gratings in the array. Such an approach allows for the identification of the characteristic wavelength change with strain of each of the sensors reflecting back a signal-the Gaussian peak of the signal is used to indicate the wavelength.

In this tests carried out, one of the available 8 channels from the optoelectronic interrogation system discussed previously (based on WDM technology) is used [8]. This incorporates a $20 \mathrm{~mW} 1520-1560 \mathrm{~nm}$ broadband light source, a Fabry-Perot 


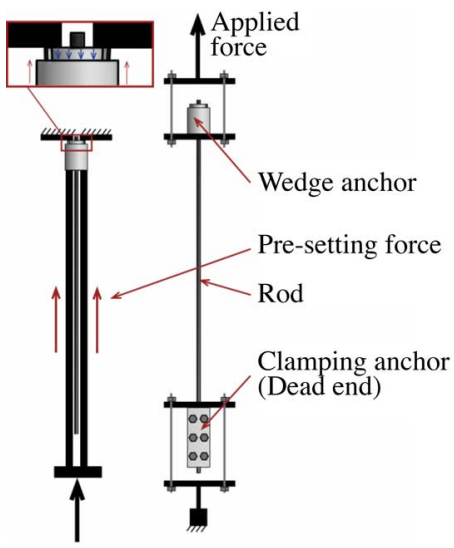

(a)

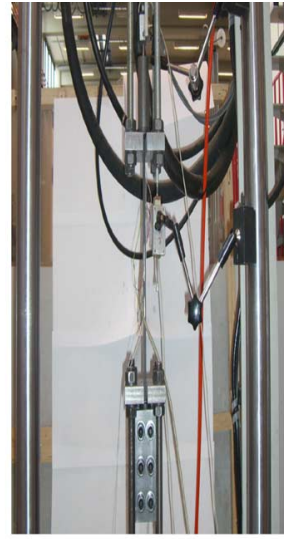

(b)
Fig. 3. (a) Left schematic of the CRFP rod containing the strain sensors loaded in the pulling machine and (b) photograph of the rod actually loaded into the machine used for this test.

spectrometer, an eight-way optical fiber splitter, an eight PIN photodiode detectors, an eight-analogue channel digital sampling processor DSP (AdwinGold), and is connected to the computer via the USB port for data storage, analysis, and transfer. The wavelength of the sensors and thence from the calibration the value of the strain (and the data to enable the required temperature correction measurements to be made from an unstrained sensor) are determined. LabView-based programming is used to undertake the analysis by determining the position of the peaks in the optical spectra obtained from the light reflected back from each sensor.

\section{Evaluation OF THE SENSOR SyStem Under LOADING}

\section{A. Installation in the Pulling Test Machine}

A series of tests to evaluate the effect of loading created through installing the CFRP rod, as shown in Fig. 2(b). In a computer controlled load machine which is used to pull and thus strain the CFRP rod. The pulling force is increased linearly under computer control from 0 to $30 \mathrm{kN}$, this being held for some time before releasing and allowing it to return back to $0 \mathrm{kN}$. Similarly, a second test was carried out over a lower force range from 0 to $20 \mathrm{kN}$ but this is repeated five times over a short period. Fig. 3 shows the CFRP rod installed in the pulling machine (INSTRON 8200), both schematically (on the left) and in an actual photograph.

\section{B. Results of the Pulling Tests}

Data were obtained from a series of tests carried out and the following graphs show strain measurement taken during the pulling tests, using forces up to 20 and $30 \mathrm{kN}$, respectively. Fig. 4 shows one cycle of data obtained from the $0-30 \mathrm{kN}$ test-and data from four of the sensors FBG 1-4. (It was discovered after the tests began that one of the sensors did not give a reading - this may have been due to a problem created during the fabrication. It was, however, decided to continue with the tests given the functionality of the other grating sensors and the likelihood of obtaining useful data from them).

The results obtained from the working sensors (in total) show that the strain varies across the rod itself with different values

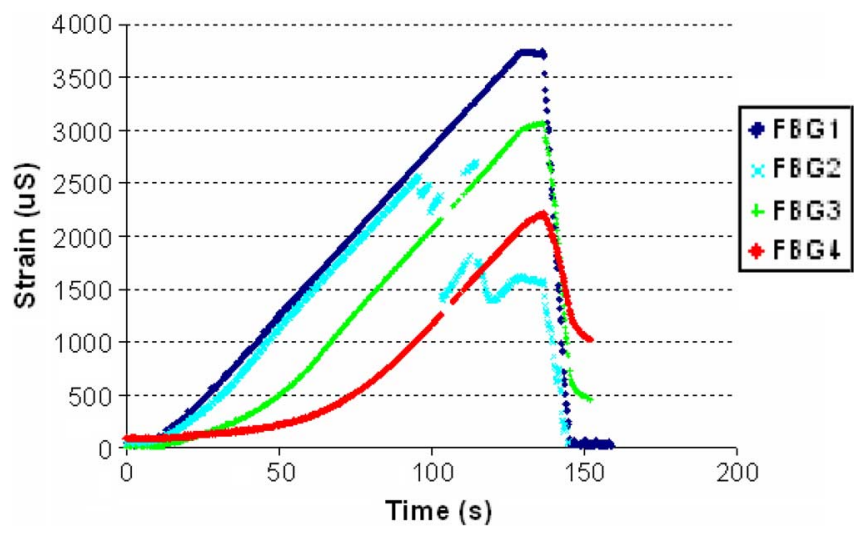

Fig. 4. Strain measurement from one cycle of the $0-30 \mathrm{kN}$ test for FBG 1-4.

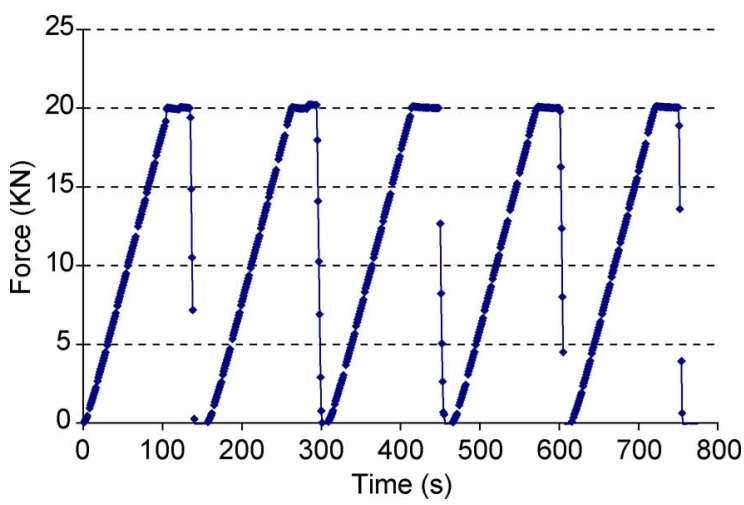

Fig. 5. Graph showing the data from the pulling test machine indicating the force applied in the $0-20 \mathrm{kN}$ test: five cycles over a period of $750 \mathrm{~s}$ is used.

of peak strain for the different sensors. Also, the results from FBG2 seem anomalous, showing a different profile from that of the other sensors. That could be due to partial debonding of the sensor to the CFPR rod over the few millimeters of the sensor length due to the very high level of force applied or a poorer writing of the grating and thus a different optical response from the sensor. Given the consistency of the response of the other three sensors, the data from this sensor can be ignored in this test.

Fig. 5 shows the temporal profile of the force applied (data read out from a on-board computer to the INSTRON 8200 machinery) for the 5 cycle, $0-20 \mathrm{kN}$ test that was carried out on the test piece containing the FBG-based sensors. Given the problem seen previously with FBG 2 and the possible damage to the sensor due to the high force $(30 \mathrm{kN})$ used, the pulling forces were decreased but several cycles of testing were used, to investigate the recovery of the sensors under this smaller loading. The results and the failure of one of the FBGs after this test suggest that the maximum force of $30 \mathrm{kN}$ is excessive for the bonded gratings used.

The system software is designed to monitor the wavelength shift of the FBGs and thus determine the applied strain using data obtained from determining either the transmission spectral peak or the Gaussian reflection peak. As can be seen from data from the five sensors positioned differently along the fiber and thus inside the rod (labeled FBG 1-4 and FBG 6-sensor FBG 5 failed to function), the strain level varies with the position of 


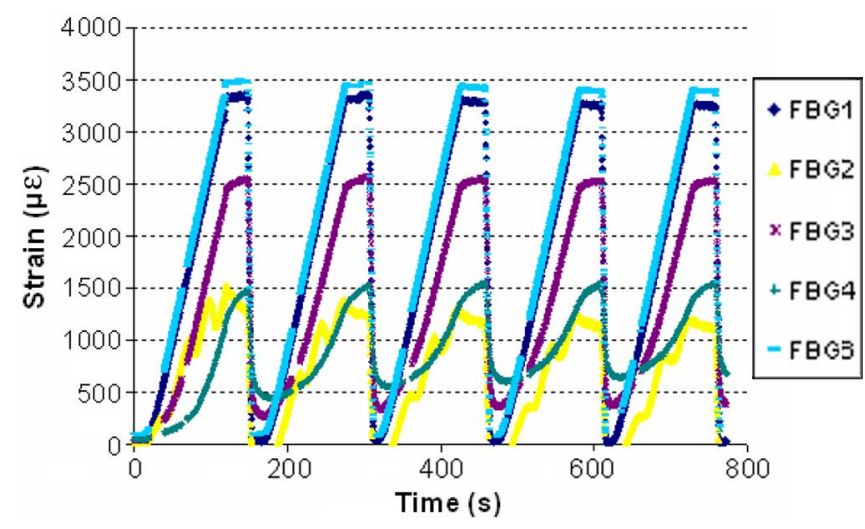

Fig. 6. Strain measurement from the 5 cycle $\times 0-20 \mathrm{kN}$ test, showing the responses of the different sensors placed along the CRPF rod.

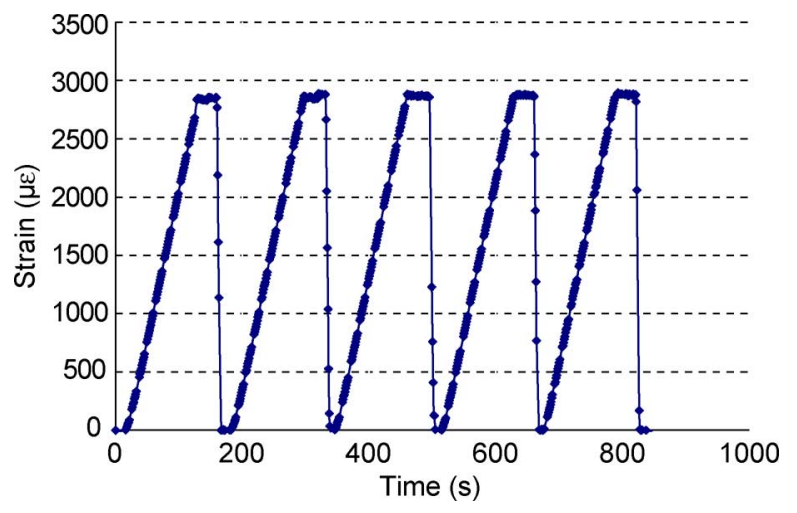

Fig. 7. Strain measurement from the single electrical strain gauge used in monitoring the five cycle $0-20 \mathrm{kN}$ test.

the sensor with respect to each cycle of the pulling force applied. The results show that there is quite a difference in the strain experienced at each of the closely spaced sensors over the $60 \mathrm{~mm}$ distance. For example, FBG 4 shows less than 50\% the maximum strain reported by FBG 6 . From the following graphs it is evident that strain levels are decreasing in region 1 to 6 direction except for FBG 6 having a high strain level which was unexpected. However, FBG 2 shows typically about $30 \%-35 \%$ of the maximum strain experienced by FBG 6 and it seems likely from the data obtained and the profile of the response that FBG 2 had been damaged permanently by the $0-30 \mathrm{kN}$ test carried out previously - a similar anomalous pattern was seen and thus the data from this sensor should be ignored. From the graph shown in Fig. 6, it is evident that strain levels are highest in FBG 1, which is positioned just outside the rod, and at FBG 6 at the end of the rod. The level of the strain for the other sensors varies as can be seen from the data on Fig. 7.

For comparison, data from the single conventional resistance strain gauge are shown in Fig. 7 for the same five cycle 0-20 kN test. This shows strain measurement where the larger electrical strain gauge is placed on the rod and located near the anchor. As expected, the data follow quite closely those of Fig. 5 (from the calibration of the pulling machine) and of the optical sensors, in particular FBG 1 (which is located physically closest to the electrical strain gauge-see Fig. 2(b) and interestingly FBG6 which, as can be seen from the figure, is located at the other end of the fiber.
TABLE I

STRAIN MEASUREMENTS From FIVE SENSORS CORRESPONDING TO DIFFERENT Pulling Forces. The Shear Stress Along the Tendon Has BeEN Calculated and PResented in TABle II for SEVERAl Situations

\begin{tabular}{|l|l|l|l|l|l|l|}
\hline $\begin{array}{l}\text { Strain } \\
\mu \varepsilon \mathrm{X} \\
10^{2}\end{array}$ & $\varepsilon_{1}$ & $\varepsilon_{2}$ & $\varepsilon_{3}$ & $\begin{array}{l}\varepsilon_{4} \\
\text { (sensor } \\
\text { bonding } \\
\text { may } \\
\text { have been } \\
\text { damaged) }\end{array}$ & $\begin{array}{l}\varepsilon_{5} \\
\text { (sensor } \\
\text { not } \\
\text { functio } \\
\text { ning) }\end{array}$ & $\varepsilon_{6}$ \\
\hline $5 \mathrm{kN}$ & 3.6 & 2.1 & 1.8 & 0.90 & - & 4.90 \\
\hline $10 \mathrm{kN}$ & 11.7 & 5.7 & 4.8 & 1.7 & - & 12.7 \\
\hline $15 \mathrm{kN}$ & 19.9 & 8.9 & 11.5 & 3.2 & - & 21.2 \\
\hline $20 \mathrm{kN}$ & 33.3 & 15.0 & 24.5 & 12.0 & - & 34.8 \\
\hline
\end{tabular}

TABLE II

SHEAR STRESS MEASUREMENTS CORRESPONDING TO DIFFERENT PULLING FORCES

\begin{tabular}{|l|c|c|c|c|}
\hline $\begin{array}{l}\text { Stress between } \\
\text { FBG a } \\
\text { position a) } \\
\text { and FBG b at } \\
\text { position b }\end{array}$ & $\varepsilon_{2}-\varepsilon_{1}$ & $\varepsilon_{3}-\varepsilon_{2}$ & $\varepsilon_{4}-\varepsilon_{3}$ & $\varepsilon_{6}-\varepsilon_{4}$ \\
\hline $\begin{array}{l}\text { Calculated } \\
\text { Sheer Stress } \\
\downarrow \text { Force }\end{array}$ & $\tau\left(\varepsilon_{2}-\varepsilon_{1}\right)$ & $\tau\left(\varepsilon_{3}-\varepsilon_{2}\right)$ & $\tau\left(\varepsilon_{4}-\varepsilon_{3}\right)$ & $\tau\left(\varepsilon_{6}-\varepsilon_{4}\right)$ \\
\hline $5 \mathrm{kN}$ & $-5.08 \times 10^{6}$ & $-0.85 \times 10^{6}$ & $-2.97 \times 10^{6}$ & $6.60 \times 10^{6}$ \\
\hline $10 \mathrm{kN}$ & $-19.63 \times 10^{6}$ & $-30.03 \times 10^{6}$ & $-10.16 \times 10^{6}$ & $18.13 \times 10^{6}$ \\
\hline $15 \mathrm{kN}$ & $-36.39 \times 10^{6}$ & $8.71 \times 10^{6}$ & $-27.32 \times 10^{6}$ & $29.63 \times 10^{6}$ \\
\hline $20 \mathrm{kN}$ & $-60.22 \times 10^{6}$ & $31.11 \times 10^{6}$ & $-41.05 \times 10^{6}$ & $37.60 \times 10^{6}$ \\
\hline
\end{tabular}

From Fig. 6, it is possible to calculate the shear stress at the surface between the tendon and the anchor. The following expression is relevant to understanding that situation [13]:

$$
\tau=E_{f r p} \cdot \frac{D}{4} \cdot \frac{\varepsilon_{i+1}-\varepsilon_{i}}{x_{i+1}-x_{i}}
$$

where $\tau$ is the calculated shear stress, $D$ is the diameter, and $E_{f r p}$ is the Young's modulus of the tendon respectively ( $D=$ $8 \mathrm{~mm}$ and $\left.E_{f r p}=165 \mathrm{GPa}\right) . \varepsilon_{i}$ is the measured strain in the various Bragg sensors ( $\mathrm{FBG}_{\mathrm{i}}$, where $i=1$ to 6 ) and $x$ is the distance between these sensors. Data calculated are tabulated in Table I.

The shear stress distribution inside the anchor is plotted in Fig. 8, and from the data obtained it can be seen that shear stress is not linear along the CFRP.

\section{DISCUSSION}

The tests have shown the capability of a short optical network (of length $\sim 60 \mathrm{~mm}$ ) containing six different optical fiber sensors to show the different strains experienced along a CFPR rod subjected to a series of cycles of strains of up to $20 \mathrm{kN}$ and $30 \mathrm{kN}$ in separate tests. Of the six installed sensors, one failed to perform (FBG 5) and one (FBG2) appeared to have been damaged or partially debonded by the first test using the largest force of $30 \mathrm{kN}$. The response shows a range of different strains along the length of the rod but overall the response of the optical sensors is seen to mirror that of the one conventional resistance strain gauge located near to the optical fiber network. Using the data 


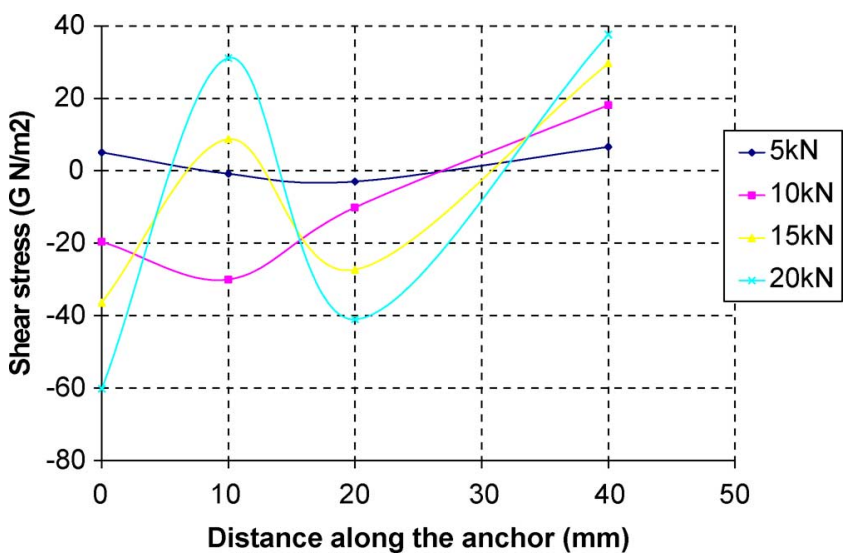

Fig. 8. The shear stress distribution inside the anchor strain measurement from the single electrical strain gauge used in monitoring the five cycle $0-20 \mathrm{kN}$ test.

obtained from the sensors, the shear stress is calculated inside the anchor itself and the results have shown that this is not linear along the CFRP.

In spite of the failure of two of the FBG sensors, these results obtained from the other four shows the value of placing the series of sensors along the rod in order to obtain information about the strain profile along its length. The results confirm the value of the use of such a sensor network for the monitoring of in situ strains on CFPR rods used in structural reinforcement and further tests in that direction are planned. By using the measured strains in the rod it was possible to calculate the shear stress in-between the wedges and the tendon. It was shown by the developed configuration it was possible to avoid peak stresses in the anchorage.

\section{ACKNOWLEDGMENT}

The authors are pleased to acknowledge the support of the Engineering and Physical Sciences Research Council through various schemes.

\section{REFERENCES}

[1] A. Al-Mayah, K. Soudki, and A. Plumtree, "Experimental and analytical investigation of a stainless steel anchorage for CFRP prestressing tendons," PCI Journal, vol. 46, no. 2, pp. 88-100, 2001.

[2] V. M. Karbhari, "Use of composite materials in civil infrastructure in Japan,” International Technology Research Institute, Word Technology Division, 1998.

[3] ACI Committee 440, "State-of-the-art report on fiber reinforced plastic (FRP) reinforcement for concrete structures (ACI 440R-96)," (Reapproved 2002) American Concrete Institute. Farmington Hills, MI, p. 65, 2002.

[4] S. K. T. Grattan, P. A. M. Basheer, S. E. Taylor, W. Zhao, T. Sun, and K. T. V. Grattan, "Corrosion induced strain monitoring through fiber optic sensors," J. Phys.: Conf. Series, vol. 85, p. 012017, 2007.

[5] K. T. V. Grattan and B. T. Meggitt, Optical Fiber Sensor Technology: Fundamentals. Norwell, MA: Kluwer, 2000.

[6] , K. T. V. Grattan and B. T. Meggitt, Eds., Optical Fiber Sensor Technology: Advanced Applications. Dordrecht, The Netherlands: Kluwer, 2000, pp. 79-187.

[7] W. Boyle, F. Kerrouche, and J. Leighton, "Guidelines and current developments for the use of Fibre Bragg Grating Sensors in the rail industry," in Sustainable Bridges: Assessment for Future Traffic Demands and Longer Lives. Wroclaw, Poland: Dolnoslaskie Wydawnictwo Edukacyjne, 2007, pp. 169-180.

[8] Y. M. Gebremichael, W. Li, B. T. Meggitt, W. Boyle, K. T. V. Grattan, B. Mckinley, F. Boswell, K. A. Arnes, S. E. Aasen, B. Tynes, Y. Fonjallaz, and T. Triantafillou, "A field deployable, multiplexed Bragg grating sensor system used in an extensive highway bridge monitoring evaluation tests," IEEE Sensors J., vol. 5, no. 3, pp. 510-519, 2005.
[9] Y. M. Gebremichael, W. Li, B. T. Meggitt, and J. O. W. Boyle, "Bragggrating-based multisensor system for structural integrity monitoring of a large civil engineering structure: A road bridge in Norway," in Proc. SPIE, 2001, vol. 4596, pp. 343-348.

[10] Y. M. Gebremichael, W. Li, W. J. O. Boyle, B. T. Meggitt, K. T. V. Grattan, B. McKinley, G. F. Fernando, G. Kister, D. Winter, L. Canning, and S. Luke, "Integration and assessment of fibre Bragg grating sensors in an all-fibre reinforced polymer composite road bridge," Sens. Actuators A: Phys., vol. 118, no. 1, pp. 78-85, 2005.

[11] A. Kerrouche, J. Leighton, W. J. O. Boyle, Y. M. Gebremichael, T. Sun, K. T. V. Grattan, and B. Täljsten, "Strain measurement on a rail bridge loaded to failure using a fiber Bragg grating-based distributed sensor system," IEEE Sensors J., vol. 8, no. 12, pp. 2059-2065, 2008.

[12] A. Kerrouche, W. J. O. Boyle, Y. M. Gebremichael, T. Sun, K. T. V. Grattan, B. Täljsten, and A. Bennitz, "Field tests of fiber Bragg grating sensors incorporated into CFRP for railway bridge strengthening condition monitoring," Sens. Actuators: A. Phys., vol. 148, no. 1, pp. 68-74, 2008.

[13] E. Y. Sayed-Ahmed and N. G. Shrive, "New steel anchorage system for post-tensioning applications using carbon fibre reinforced plastic tendons," Canadian J. Civil Eng., vol. 25, no. 1, pp. 113-127, 1998.

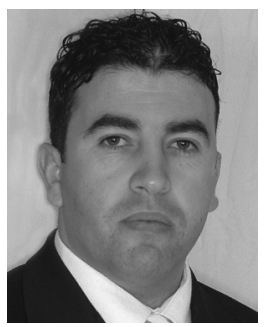

Abdelfateh Kerrouche received the M.S. degree of philosophy in electronics at Pierre \& Marie Curie Paris VI University, Paris, France, and the M.S. degree in electronics, electro-technique and automatics from Marne-La-Vallee University, Paris. He is currently working towards the Ph.D. degree at the School of Engineering and Mathematical Sciences, City University London, London, U.K.

He completed a training course at ESME-Sudria (private school of engineering) in collaboration with Tenon Hospital, Paris, to develop new software for segmentation of optical. He has finished a work placement at Oxford Brookes University in the Medical Instrumentation Laboratory to develop a computerbased system to record, store, and analyze respiratory signals during anesthesia. His research interest is strain measurement monitoring system based on fiber Bragg grating (FBG) sensors.

William J. O. Boyle is a Senior Lecturer at City University London, London, U.K.

Tong Sun received the Bachelor of Engineering, Master of Engineering, and Doctor of Engineering degrees in mechanical engineering from the Department of Precision Instrumentation, Harbin Institute of Technology, Harbin, China, in 1990, 1993, and 1998, respectively, and the Doctor of Philosophy degree in applied physics from City University, London, U.K., in 1999.

She was an Assistant Professor at Nanyang Technological University, Singapore, from 2000 to 2001 and is currently a Reader at City University. She has authored or coauthored some 110 scientific and technical papers. Her research interest is in optical fiber sensors, instrumentation, laser engineering, and optical communications.

Dr. Sun is a member of the Institute of Physics, the Institution of Engineering and Technology, a Chartered Physicist, and a Chartered Engineer in the U.K.

Kenneth T. V. Grattan was born in Co. Armagh, Northern Ireland, on December 9, 1953. He received the B.S. degree in physics (First Class Honors) and the Ph.D. degree from The Queen's University, Belfast, in 1974 and 1978, respectively, and the Doctor of Science degree from City University, London, U.K., in 1992.

In the same year, he became a Postdoctoral Research Assistant at Imperial College, London, U.K. He joined City University, London, in 1983 after five years at Imperial College, undertaking research in novel optical instrumentation, especially in fiber-optic sensor development for physical and chemical sensing. The work has led into several fields including luminescence-based thermometry, Bragg-grating-based strain sensor systems, white-light interferometry, optical system modeling, and design and optical sensors for water quality monitoring. The work has been extensively published in the major journals and at international conferences in the field, where regularly he has been an invited 
speaker, and over 600 papers have been authored to date. Multimillion dollar sponsorship for the work has come from industry, the research councils in the U.K., the European Union, and the Professional Bodies, with over 40 Ph.D. students graduating during that time. He is currently Deputy Dean of Engineering at City University, having been from 1991 to 2001 Head of the then Electrical, Electronic and Information Engineering Department. His research during that period was on laser systems for photophysical systems investigations, and he and his colleagues constructed some of the first of the then new category of excimer lasers (XeF, $\mathrm{KrF}$ ) in Europe in 1976. His work in the field continued with research using ultraviolet and vacuum ultraviolet lasers for photolytic laser fusion driver systems and studies on the photophysics of atomic and molecular systems.

Prof. Grattan was Chairman of the Applied Optics Division of the U.K. Institute of Physics and President of the Institute of Measurement and Control in 2000.

Jacob W. Schmidt is working towards the Ph.D. degree at Technical University, Lyngby, Denmark (DTU).
Björn Täljsten is a Project Manager for national and international construction and R\&D projects. He is a specialist in the following areas: concrete structures and concrete repair, use of polymer composites in construction, structural health monitoring and risk management-in particular, technical risk management. He is an experienced project leader both in construction and R\&D related projects and developed composite strengthening systems for bridges, in particular, NSMR (Near Surface Mounted Reinforcement) CFRP rods, from 1997 to the present, and carbon fiber rods that are bonded in the concrete cover in a structure. This system has today been widely accepted worldwide. We have installed it with success on several bridges in Sweden. The system can also be prestressed. He developed a completely new strengthening system, during 2005-2007, where carbon fiber tubes are bonded in drilled holes in the structure. This system was developed due to the need for strengthening without interrupting the ongoing traffic. It has so far been used on one bridge, the Frövi Bridge outside Örebro, Sweden, to strengthening a concrete slab in flexure, just under the ballast. He developed SHM (structural health monitoring) strategies for periodic and continuous monitoring of bridges both in service and for ultimate. This to optimize and bring down the need for maintenance and monitored several bridges with consideration to verify strengthening effects and performance. 